\title{
Postnatal Adrenoreceptor Maturation in Porcine Intrapulmonary Arteries
}

\author{
LOUISE E. WILSON, MARILYNE LEVY, KAREN STUART-SMITH. AND SHEILA G. HAWORTH

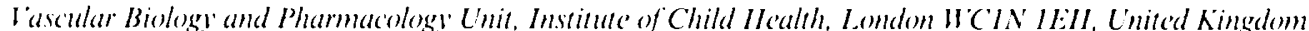

\begin{abstract}
ABSTRACI. The effect of postnatal age on norepinephrine-induced $\alpha_{2}$-adrenoreceptor-mediated release of endothelium-derived relaxing factor in porcine intramuscular pulmonary arteries was studied. Rings of pulmonary artery from fetal, newborn, 3-d-, 10-d-, 9-wk-, and 15-wk-old pigs with and without endothelium were suspended for isometric force measurement in Krebs-Ringer bicarbonate solution $\left(37^{\circ} \mathrm{C}, 95 \% \quad \mathrm{O}_{2}-5 \% \quad \mathrm{CO}_{2}\right)$. In $15-$ and 10 -wk-old pigs, norepinephrine increased tone in arteries with and without endothelium but produced relaxations at high concentrations only in arteries with endothelium. These relaxations were not inhibited by the $\alpha_{1}$-antagonist prazosin but were completely abolished by the $\alpha_{2}$-antagonist yohimbine and the inhibitor of nitric oxide release $\mathbf{N}-\omega$-nitro-L-arginine methyl ester. This confirms that the norepinephrine-induced relaxations were due to $\alpha_{2}$-mediated release of endothelium-derived relaxing factor. Arteries from only $50 \%$ of the 10-d-old animals showed endothelium-dependent relaxations, and at $3 \mathrm{~d}$ of age and younger no relaxations were seen. In animals less than $10 \mathrm{~d}$ old, only some of the vessels contracted to norepinephrine and the contractile response was diminished compared with 15-wk-old animals, whereas the response to prostaglandin $\mathrm{F}_{2} \alpha$ and histamine was similar in the neonatal group (newborn, $3 \mathrm{~d}$ old, and $10 \mathrm{~d}$ old). This group showed a dose-dependent relaxation to nitric oxide, with $\mathbf{1 0 - d - o l d ~ a n i m a l s ~ m o r e ~}$ sensitive to nitric oxide than newborn animals. Thus, maturational changes occur in adrenergic-mediated contraction, in the modulation of contractility by endothelial $\alpha_{2}-$ adrenoreceptors and in the response to nitric oxide. ( $P e$ diatr Res 34: 591-595, 1993)
\end{abstract}

\section{Abbreviations}

EDRF, endothelium-derived relaxing factor LNAME, $N$ - $\omega$-nitro-L-arginine

$\mathrm{PGF}_{2 \alpha}$, prostaglandin $\mathrm{F}_{2 \alpha}$

$\mathrm{EC}_{50}$, effective concentration causing $50 \%$ of the maximal contractile response

The endothelium plays an important role in the regulation of vasomotor tone, producing smooth muscle constricting factors such as endothelin and relaxing factors including EDRF, now identified as nitric oxide (1-3). The vasodilator action of several substances such as acetylcholine, bradykinin, and substance $P$ are dependent on the release of such factors $(4,5)$.

Maturational changes have been demonstrated in the vasodilator response to acetylcholine in porcine intrapulmonary arteries

Received February 14, 1992: accepted June 22, 1993

Correspondence and reprint requests: Professor S. G. Haw orth. Institute of Child Health, 30 Guilford St., London WCIN 1EH, UK.

Supported by the British Heart Foundation. Smith Industries, and Commission of the European Communities.
(6-8). Such changes may be important in the mechanism underlying the reduction in pulmonary vascular resistance that occurs at birth. Structural vascular reorganization (9-11), establishment of ventilation (12), and alteration in the local production of vasoactive substances $(13,14)$ may also contribute to the changes that occur in the pulmonary circulation at this time.

Previous studies from this laboratory have shown that norepinephrine can produce relaxation by $\alpha_{2}$-adrenoreceptor-mediated EDRF release in isolated adult porcine intrapulmonary arteries (15). We hypothesized that there are maturational changes in pulmonary arterial endothelium-dependent $\alpha_{z}$-adrenoreceptor-mediated relaxation. We investigated this hypothesis using isolated porcine intrapulmonary arteries from fetal, newborn, 3- and 10-d-old, and 10- and 15-wk-old pigs.

\section{MATERIALS AND METHODS}

Intrapulmonary arteries were studied from four fetal pigs ( 3 wh premature) and from 30 animals less than $2 \mathrm{~h}, 3 \mathrm{~d}, 10 \mathrm{~d}, 10$ wk, and 15 wk old. Animals received humane care in compliance with the Principles of Laboratory Animal Care formulated by the National Society of Medical Research and the Guide for the Care and Use of Laboratory Animals prepared by the National Academy of Science and published by the National Institutes of Health (NIH publication no. 80-23, revised 1978). The pigs were anesthetized with either sodium pentobarbitone (fetal to 10-dold animals) or halothane (10- and 15-wk-old animals) and killed by exsanguination. Fetal and newborn lungs were each obtained from a single litter: all other lungs were from at least three litters. The lungs were placed in ice-cold Krebs-Ringer bicarbonate (composition in mmol: $118.3 \mathrm{NaCl}, 4.7 \mathrm{KCl}, 2.5 \mathrm{CaCl}_{2}, 1.2$ $\mathrm{MgSO}_{4}, 1.2 \mathrm{KH}_{2} \mathrm{PO}_{4}, 25 \mathrm{NaHCO}_{3}, 0.026$ calcium disodium edetate, 11.1 glucose). The distal portion of the muscular intrapulmonary artery was dissected out and cleaned of connective tissue before being cut into rings approximately 3-4 $\mathrm{mm}$ long. In each animal, rings with and without endothelium were studied. The endothelium was removed by gently rubbing the luminal surface with watchmaker's forceps. Rings were suspended in 25$\mathrm{mL}$ organ baths filled with Krebs solution at $37^{\circ} \mathrm{C}$ and bubbled with $95 \% \mathrm{O}_{2}-5 \% \mathrm{CO}_{2}$ and attached to a Grass FTO3 transducer (Grass Instrument Co., Quincy, MA). Isometric forces were recorded on a model 7 Grass polygraph.

Each ring was stretched progressively to its optimal point on the length tension curve as determined by the maximal force developed in response to $40 \mathrm{mmol}$ of $\mathrm{KCl}$. After optimal tension was achieved, the pulmonary artery rings were equilibrated for 1 $\mathrm{h}$ before the experimental protocols were commenced. At the end of the experiment, the rings were fixed in glutaraldehyde, embedded in araldite, cut in $1-\mu \mathrm{m}$ sections, and stained with toluidine blue to confirm the presence or absence of endothelium. For each experimental protocol, between four and nine rings were used in each age group, each ring from a different animal.

Experimental protocols. In animals of all ages, cumulative concentration response curves to norepinephrine $10^{-4}$ to $10^{-4} \mathrm{M}$ 
were obtained by adding the drug in half-log increments. The cyclooxygenase inhibitor indomethacin $\left(10^{-5} \mathrm{M}\right)$ was added 30 min before the experiment and was present throughout the study.

Norepinephrine concentration response curves were also produced in rings that had been incubated with either the inhibitor of nitric oxide release, LNAME $\left(3 \times 10^{-6} \mathrm{M}\right)$, the $\alpha_{1}$-adrenergic receptor antagonist prazosin $\left(10^{-7} \mathrm{M}\right)$, or the $\alpha_{2}$-adrenergic receptor antagonist yohimbine $\left(10^{-6} \mathrm{M}\right)$. Inhibitors and antagonists were added $30 \mathrm{~min}$ before the start of the experiment and remained present throughout the time the concentration response curve to norepinephrine was being constructed. Preliminary experiments showed that these drugs had no effect on baseline tone. After completion of the norepinephrine concentration response curve, rings from newborn, 3-d-old, and 10-dold animals were washed until the baseline tone was regained and then exposed to histamine $\left(10^{-4} \mathrm{M}\right)$.

At the end of all the experiments, sodium nitroprusside was given to check that the smooth muscle cells were capable of relaxation. Also, in denuded vessels a dose of acetylcholine preceded the addition of sodium nitroprusside to check for the absence of endothelial cells.

In a second series of experiments, pulmonary arteries from newborn, 3-d-old, and 10-d-old animals were contracted with $\operatorname{PGF}_{2 a}\left(10^{-5} \mathrm{M}\right)$ in the presence of indomethacin $\left(10^{-5} \mathrm{M}\right)$. A concentration response curve to nitric oxide $\left(10^{-8.5}\right.$ to $10^{-5.5} \mathrm{M}$ in log molar increments) was then constructed.

Nitric oxide preparation. Helium was bubbled through distilled water for $3 \mathrm{~h}$ to remove dissolved oxygen. Nitric oxide was then bubbled through this solution for $1 \mathrm{~h}$ to produce a saturated solution of nitric oxide. This was then serially diluted in distilled water pregassed with helium.

Drugs. The following drugs were obtained from Sigma Chemical Company, Poole, UK: +/- norepinephrine hydrochloride. indomethacin, prazosin hydrochloride, yohimbine hydrochloride, LNAME, histamine dihydrochloride, and $\mathrm{PGF}_{2, \text { ar }}$. Nitric oxide was obtained from Merck, Poole, UK. Drugs were added in $100-\mu \mathrm{L}$ aliquots, and the concentrations of drugs are reported as the final molar concentration in the organ bath.

Data analysis. In each experiment with or without antagonists, the response at each concentration of norepinephrine is expressed as a percentage of the maximal contractile response to norepinephrine obtained. In the case of relaxation responses, results are expressed as percentage relaxation of the $\mathrm{PGF}_{2 x}$-induced tone. Results are expressed as mean \pm SD. Where appropriate, the $\mathrm{EC}_{50}$ was calculated for individual curves and the mean of these values reported as the negative logarithm of the molar concentration. The $t$ test was used to compare $\mathrm{EC}_{50}$ values and responses at maximal concentrations of norepinephrine. Values less than $p<0.05$ were considered significant.

\section{RESULTS}

At all ages, there was no significant difference in resting tension in pulmonary arteries with endothelium compared with arteries denuded of endothelium. There was no significant difference in the weight of the pulmonary artery rings at different ages.

Effect of norepinephrine. In all 15-wk-old pigs, norepinephrine produced a concentration-dependent increase in tone in arteries with and without endothelium (Fig. $1 a$ ). However, at high concentrations $\left(10^{-5.5}\right.$ to $\left.10^{-4} \mathrm{M}\right)$, all arteries with endothelium showed a relaxation (Fig. $1 a$, Table 1 ). In the presence of the $\alpha_{1}$ antagonist prazosin $\left(10^{-7} \mathrm{M}\right)$, endothelium-dependent relaxations to norepinephrine were still present at high concentrations (Table 1). Arteries without endothelium showed only a dosedependent increase in tone. In arteries both with and without endothelium, the norepinephrine concentration response curves tended to be shifted to the right in the presence of the antagonist. In the presence of the $\alpha_{2}$-antagonist yohimbine $\left(10^{-6} \mathrm{M}\right)$ arteries both with and without endothelium showed only a dose-dependent increase in tone with norepinephrine, and the concentration
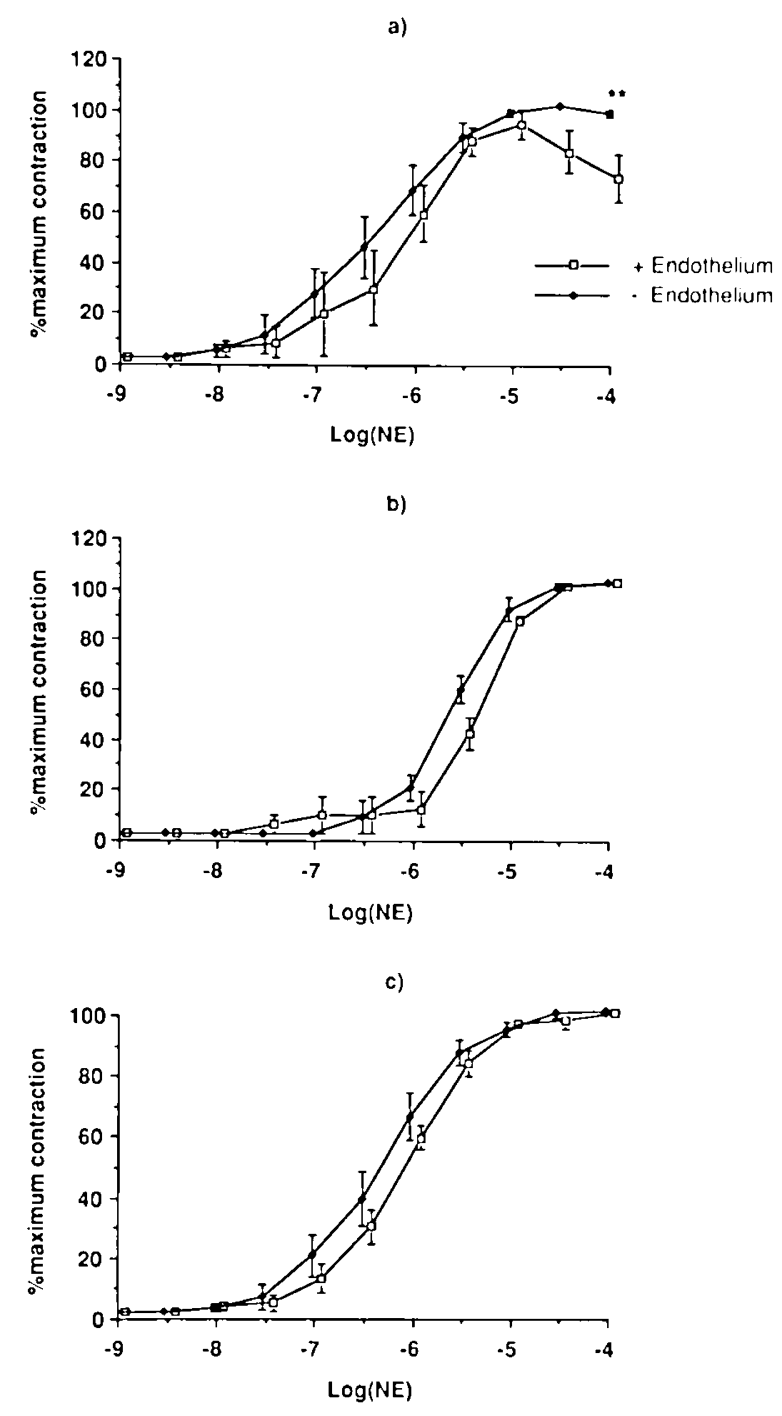

Fig. 1. Cumulative concentration response curves to norepinephrine $(N E)$ in rings of pulmonary artery from 15 -wk-old pigs with and without endothelium. Data shown as mean \pm SEM. $a$. Control: $h$, in the presence of yohimbine $\left(10^{-6} \mathrm{M}\right)$, and $c$, in the presence of LNAME $\left(3 \times 10^{-6} \mathrm{M}\right)$. ${ }^{* *}, p<0.05$ comparing rings with and without endothelium.

response curves were significantly shifted to the right $(p<0.05)$ (Table 1, Fig. 1b). In the presence of the inhibitor of nitric oxide release LNAME $\left(3 \times 10^{-6} \mathrm{M}\right)$, norepinephrine produced an increase in tone in both arteries with and without endothelium, but no endothelium-dependent relaxation occurred at high concentrations of norepinephrine (Table 1. Fig. Ic).

As in the 15-wk-old animals, in pulmonary artery rings from 10-wk-old pigs, norepinephrine produced a concentration-dependent increase in tone in arteries with and without endothelium (Table 2). Only arteries with endothelium showed relaxations to norepinephrine in the dose range $10^{-5}$ to $10^{-4} \mathrm{M}$ (Table 3). There was no difference in the maximum contraction to norepinephrine or the $\mathrm{EC}_{50}$ between the 10 - and 15-wk-old animals.

At $10 \mathrm{~d}$ of age, norepinephrine increased tone in all pulmonary arteries, both with and without endothelium (Table 2). The maximum contractile response to norepinephrine was significantly less than in the 15 -wk-old animals $(p<0.001)$. Only four of eight arteries with endothelium showed relaxations to norepinephrine in the concentration range $10^{-4.5}$ to $10^{-4} \mathrm{M}$ and no artery without endothelium relaxed (Table 3 ).

At $3 \mathrm{~d}$ of age, six of nine pulmonary arteries with endothelium and seven of nine arteries without endothelium responded to 
Table 1. Relaxation response to norepinephrine $10^{-4} \mathrm{M}$ as a percentage of maximal response' to norepinephrine and EC 50 for 15 wk-old animals (mean $\pm S E M$ )*

\begin{tabular}{|c|c|c|c|c|c|c|}
\hline & \multicolumn{3}{|c|}{ With endothelium $(n=5)$} & \multicolumn{3}{|c|}{ Without endothelium $(n=5)$} \\
\hline & $\begin{array}{c}\text { Max cont } \\
(\mathrm{g})\end{array}$ & $\begin{array}{c}\text { \% Contraction } \\
\text { remaining }\end{array}$ & $E C_{50}$ & $\begin{array}{l}\text { Max cont } \\
(\mathrm{g})\end{array}$ & $\begin{array}{c}\% \text { Contraction } \\
\text { remaining }\end{array}$ & $E C_{50}$ \\
\hline Control & $2.03 \pm 0.31$ & $71.5 \pm 9.52$ & $6.20 \pm 0.27$ & $2.23 \pm 0.35$ & $96.70 \pm 1.34$ & $6.50 \pm 0.27$ \\
\hline Prazosin & $2.86 \pm 1.12$ & $79.5 \pm 5.36 \dagger$ & $5.70 \pm 0.09 \dagger$ & $2.40 \pm 0.58$ & 100 & $5.70 \pm 0.137$ \\
\hline Yohimbine & $1.77 \pm 0.53$ & $100 \ddagger$ & $5.40 \pm 0.09 \ddagger$ & $1.32 \pm 0.35$ & $98.30 \pm 1.65 \dagger$ & $5.60 \pm 0.09 \$$ \\
\hline LNAME & $2.63 \pm 0.71$ & $98.8 \pm 0.80 \ddagger$ & $6.12 \pm 0.09 \dagger$ & $2.07 \pm 0.62$ & $99.40 \pm 0.58+$ & $6.30 \pm 0.13 \dagger$ \\
\hline
\end{tabular}

* Max cont, maximum contraction.

+ NS compared with the control value.

$\ddagger p<0.05$ compared with the control value.

$\$ p<0.02$ compared with the control value.

Table 2. Maximal contractile response to $N E$ with age and $E C_{50}(m e a n \pm S E M)^{*}$

\begin{tabular}{|c|c|c|c|c|c|}
\hline Age group & Endothelium & $\begin{array}{l}\text { Rings } \\
\text { studied } \\
(n) \dagger\end{array}$ & $\begin{array}{l}\text { Rings con- } \\
\text { tracting }(n)\end{array}$ & $\begin{array}{c}\text { Max NE resp } \\
\text { (g) }\end{array}$ & $\mathrm{EC}_{\mathbf{s}_{0}}$ \\
\hline \multirow[t]{2}{*}{$15 \mathrm{wk}$} & + & 5 & 5 & $2.03 \pm 0.31$ & $6.20 \pm 0.27 \ddagger$ \\
\hline & - & 5 & 5 & $2.23 \pm 0.35$ & $6.50 \pm 0.27 \$$ \\
\hline \multirow[t]{2}{*}{$10 w k$} & + & 4 & 4 & $1.92 \pm 0.45$ & $5.92 \pm 0.10 \$$ \\
\hline & - & 4 & 4 & $1.90 \pm 0.22$ & $6.09 \pm 0.15 \$$ \\
\hline \multirow[t]{2}{*}{$10 \mathrm{~d}$} & + & 8 & 8 & $0.32 \pm 0.14 \|$ & $5.70 \pm 0.14 \ddagger$ \\
\hline & - & 8 & 8 & $0.43 \pm 0.04$ & $5.90 \pm 0.17 \ddagger$ \\
\hline \multirow[t]{2}{*}{$3 \mathrm{~d}$} & + & 9 & 6 & $0.18 \pm 0.06 \|$ & $5.06 \pm 0.12$ \\
\hline & - & 9 & 7 & $0.25 \pm 0.09$ & $5.12 \pm 0.15$ \\
\hline \multirow[t]{2}{*}{ Newborn $(<2 \mathrm{~h})$} & + & 4 & 1 & 0.10 & 4.50 \\
\hline & - & 4 & 0 & 0 & \\
\hline \multirow[t]{2}{*}{ Fetal } & + & 4 & 2 & $0.25 \pm 0.05$ & $4.90 \pm 0.34$ \\
\hline & - & 4 & 4 & $0.38 \pm 0.07$ & $6.30 \pm 0.70$ \\
\hline
\end{tabular}

* NE, norepinephrine; $\max$ NE resp, maximum NE response.

+ One ring with and one ring without endothelium per animal.

$\ddagger p<0.02$ compared with 3 -d group.

$\$ p<0.01$ compared with 3 -d group.

$\| p<0.001$ compared with 15 -wk group and with 10-wk group.

Table 3. Relaxation response to norepinephrine $10^{-4}$ M as a percentage of maximal contractile response to norepinephrine

\begin{tabular}{|c|c|c|c|c|c|c|}
\hline \multirow[b]{2}{*}{ Age group } & \multicolumn{3}{|c|}{ With endothelium } & \multicolumn{3}{|c|}{ Without endothelium } \\
\hline & $\begin{array}{c}\text { Rings } \\
\text { studied } \\
(n)^{*}\end{array}$ & $\begin{array}{l}\text { Rings } \\
\text { relaxing } \\
(n)\end{array}$ & $\begin{array}{c}\text { \% Relaxation } \\
\text { response }\end{array}$ & $\begin{array}{c}\text { Rings } \\
\text { studied } \\
(n)^{*}\end{array}$ & $\begin{array}{c}\text { Rings } \\
\text { relaxing } \\
(n)\end{array}$ & $\begin{array}{c}\text { Relaxation } \\
\text { response }\end{array}$ \\
\hline $15 w k$ & 5 & 5 & $71.50 \pm 9.52$ & 5 & 5 & $96.70 \pm 1.34$ \\
\hline $10 w k$ & 4 & 4 & $83.30 \pm 5.60 \ddagger$ & 4 & 4 & $99.30 \pm 0.75$ \\
\hline $10 \mathrm{~d}$ & 8 & 4 & $69.30 \pm 22.10 \ddagger$ & 8 & 8 & 100 \\
\hline $3 d$ & 9 & 0 & $100 \$$ & 9 & 7 & $100 t$ \\
\hline Newborn $(<2 \mathrm{~h})$ & 4 & 0 & 100 & 4 & 4 & 0 \\
\hline Fetal & 4 & 0 & 100 & 4 & 4 & 100 \\
\hline
\end{tabular}

* One ring with and one ring without endothelium per animal.

+ Comparing the response without endothelium at $15 \mathrm{wk}, 10 \mathrm{wk}$, and $10 \mathrm{~d}, p<0.05$.

$\ddagger$ NS compared with 15 wk.

$\$ p<0.01$ compared with 15 weeks.

norepinephrine with increased tone (Table 2, Fig. 2). The maximum contractile response to norepinephrine was significantly reduced compared with the 15 -wk-old animals $(p<0.001)$. The $\mathrm{EC}_{s_{0}}$ for arteries both with and without endothelium was significantly shifted to the right compared with the 10-d-and 10- and 15 -wk-old animals. Norepinephrine did not produce relaxation in any of the arteries (Table 3).

In the newborn, less than 2-h-old animals, only one of the four pulmonary arteries with endothelium contracted in response to norepinephrine, and then only at the maximal dose of $10^{-4} \mathrm{M}$ (Table 2). None of the pulmonary arteries without endothelium reacted to norepinephrine. None relaxed (Table 3 ).
In the fetal studies, two of four arteries with endothelium and four of four arteries without endothelium responded to norepinephrine (Table 2). The maximal contraction and $\mathrm{EC}_{50}$ to norepinephrine were similar to those seen in the 3-d-old animals. No relaxations to norepinephrine were seen (Table 3).

Effect of histamine on intrapulmonary arteries of newborn, 3-, and 10-d-old animals (Table 4). There was no difference in the response to histamine $\left(10^{-4} \mathrm{M}\right)$ in arteries with or without endothelium. All arteries responded to histamine, even those that had shown no response to norepinephrine. The response to histamine was similar in all age groups and larger than the response to norepinephrine. 


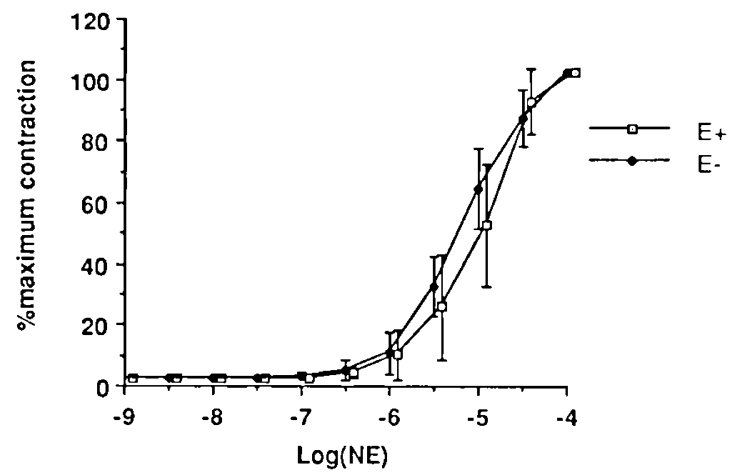

Fig. 2. Cumulative concentration response curves to norepinephrine in rings of pulmonary artery with $(E+)$ and without $(E-)$ endothelium from 3-d-old pigs. Data shown as mean \pm SEM.

Effect of nitric oxide on intrapulmonary arteries from newborn, 3-d-, and 10-d-old animals. All arteries contracted in response to $10^{-5} \mathrm{M} \mathrm{PGF}_{2 \alpha}$ (Table 4). There was no significant difference in tone generated between arteries with and without endothelium or between the different age groups. At all ages arteries precontracted with $\mathrm{PGF}_{2 x}$ showed a dose-dependent relaxation to nitric oxide with and without endothelium (Fig. 3). However, pulmonary arteries from 10-d-old animals showed a marked response to nitric oxide at $10^{-7.5} \mathrm{M}$, whereas arteries from all pigs less than $2 \mathrm{~h}$ of age and arteries from two of five animals aged $3 \mathrm{~d}$ showed no relaxation at all in response to this dose but did relax at $10^{-6.5} \mathrm{M}$ with a maximum relaxation at $10^{-5.5} \mathrm{M}$ (Fig. 3 ).

\section{DISCUSSION}

This study demonstrates that in the intralobar pulmonary artery of the pig the contractile response to norepinephrine alters with age as does the ability of the vascular endothelium to modulate the contractile response.

Fifteen-wk-old animals showed an increase in tone in response to norepinephrine in rings with endothelium at low concentrations and relaxations at high concentrations. This response was similar to that seen in the adult pig (15). The specific blocker of nitric oxide release LNAME (16) abolished the endotheliumdependent relaxation, implying that the relaxation was due to EDRF. The lack of effect of LNAME on baseline tension implies no basal release of nitric oxide. However, in vivo studies have shown that the nitric oxide synthase inhibitor monomethyl-Larginine can increase pulmonary artery pressure in the 1- to 3d-old guinea pig (17), and LNAME causes a dose-dependent increase in pulmonary artery pressure in lambs (18). The $\alpha_{1}$ adrenergic antagonist prazosin did not alter the norepinephrineinduced relaxations, but these were abolished by the $\alpha_{2}$-antagonist yohimbine. This suggests an $\alpha_{2}$-adrenergically mediated EDRF release in response to norepinephrine. We have previously demonstrated $\alpha_{2}$-mediated relaxations in the intrapulmonary arteries of the adult pig, and others have demonstrated the same response in the coronary arteries of the adult pig (19) and dog (20).

Endothelium-dependent relaxations to high doses of norepi- nephrine were seen in all the pulmonary arteries of 10 -wk-old pigs, and were present in the arteries of some of the 10-d-old animals but not in any of the younger animals. This could reflect a maturational change in receptor sensitivity, distribution, or density or in the secondary messenger system leading to release of nitric oxide, or an alteration in the ability of the vascular smooth muscle to relax to nitric oxide. These vessels are innervated by nerves that contain predominantly tyrosine hydroxylase and neuropeptide $Y$, and the pattern of innervation of these vessels does not change significantly after birth (21). In an attempt to clarify the problem, we studied the response to nitric oxide in the pulmonary arteries of newborn, 3-d-., and 10-d-old animals. Animals aged $10 \mathrm{~d}$ were significantly more responsive to nitric oxide than the newborn or 3-d-old animals. Maturational changes of increasing sensitivity to nitric oxide in pigs aged $3 \mathrm{~d}$ and older has also been shown by Zellers and Vanhoutte (7). Alterations in vascular smooth muscle responsiveness to nitric oxide may partly explain our findings and those of other groups showing diminished endothelium-dependent relaxations to acetylcholine in young pigs and lambs $(13,22)$.

The ability of the vascular smooth muscle to contract in response to norepinephrine also altered with age. In arteries from animals less than $10 \mathrm{~d}$ of age, the contractile response to norepinephrine was very variable with only some of the vessels responding. Rings from fetal and 3-d-old animals showed a response to norepinephrine more frequently than did those from newborn animals, but by $10 \mathrm{~d}$ of age and greater, all arteries responded to norepinephrine. This transitory reduction in norepinephrine responsiveness after birth is similar to that seen by Dunn et al. (23) in 3rd-generation pulmonary arteries of lambs, when arteries from fetal and 21 -d-old lambs were more responsive than arteries from $1-$ and 7 -d-old lambs. Before birth, Su ${ }^{\prime} t$ al. (5) found no change in the maximal contractile response to norepinephrine in developing fetal lambs aged from $53 \mathrm{~d}$ to term. In our study, of those arteries that did show a response to norepinephrine in the fetal, newborn, and 3-d-old age groups, there was no significant difference in $\mathrm{EC}_{50}$ with or without endothelium, and no difference in $\mathrm{EC}_{50}$ between these age groups. However, the $\mathrm{EC}_{50}$ of the 3-d-old group was significantly less than that of the 10-d, 10-wk, or 15-wk age groups, which were similar to each other. These findings suggest that a maturational change occurs in the contractile response to norepinephrine between 3 and $10 \mathrm{~d}$ of age. Again, this could represent changes in receptor sensitivity, distribution, density, or coupling of the intracellular secondary messenger with the contractile apparatus. The fact that there was no significant alteration in the magnitude of the response to histamine $\left(10^{-4} \mathrm{M}\right)$ or $\operatorname{PGF}_{2 \alpha}\left(10^{-5} \mathrm{M}\right)$ in the newborn, 3-d, or 10-d group implies that maturation of the contractile apparatus of the vascular smooth muscle cell is less likely to account for the relative lack of responsiveness to norepinephrine in the newborn and 3-d-old animals.

Buckley ot al. (24) showed that newborn to 3-mo-old piglets studied in vivo were capable of responding to norepinephrine by an increase in systemic pressure, implying functional $\alpha_{1}$-adrenoceptors on systemic arteries. Pulmonary arterial pressures were not measured. In developing lambs, isolated systemic arteries were more sensitive than intrapulmonary arteries to norepinephrine. Because birth is associated with a large increase in circulat-

Table 4. Response to histamine and $P G F_{2 \alpha}{ }^{*}$

\begin{tabular}{|c|c|c|c|c|c|c|c|c|}
\hline \multirow[b]{2}{*}{$\begin{array}{l}\text { Age } \\
\text { group }\end{array}$} & \multicolumn{4}{|c|}{ Response to histamine $10^{-4} \mathrm{M}$ in $\mathrm{g}$} & \multicolumn{4}{|c|}{ Response to $\mathrm{PGF}_{21} 10^{-5} \mathrm{M}$ in $\mathrm{g}$} \\
\hline & $n$ & $\begin{array}{l}\text { With endo- } \\
\text { thelium }\end{array}$ & $n$ & $\begin{array}{l}\text { Without en- } \\
\text { dothclium }\end{array}$ & $n$ & $\begin{array}{l}\text { With endo- } \\
\text { thelium }\end{array}$ & $n$ & $\begin{array}{l}\text { Without en- } \\
\text { dothelium }\end{array}$ \\
\hline $10 \mathrm{~d}$ & 5 & $0.51 \pm 0.06$ & 5 & $0.54 \pm 0.06$ & 4 & $0.58 \pm 0.10$ & 4 & $0.6 \pm 0.15$ \\
\hline $3 \mathrm{~d}$ & 7 & $0.45 \pm 0.06$ & 7 & $0.39 \pm 0.05$ & 5 & $0.4 \pm 0.18$ & 5 & $0.38 \pm 0.09$ \\
\hline Newborn & 4 & $0.47 \pm 0.10$ & 4 & $0.35 \pm 0.05$ & 4 & $0.36 \pm 0.15$ & 3 & $0.35 \pm 0.17$ \\
\hline
\end{tabular}

* There was no significant difference between the response to PGF $_{2, x}$ and the response to histamine at different ages or in response to either drug with age. 

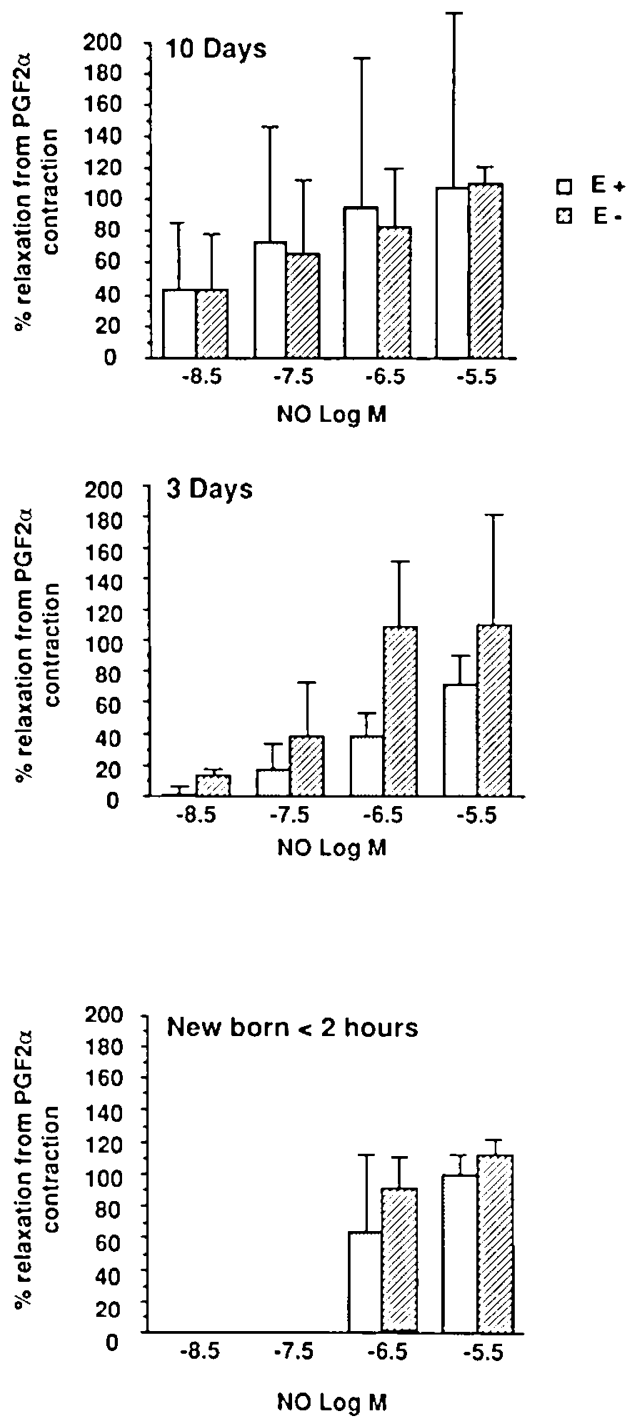

Fig. 3. Histogram showing percentage relaxation to nitric oxide in arteries precontracted with $\mathrm{PGF}_{2 \alpha}$ at different ages. Data shown as mean \pm SEM.

ing catecholamines, a selective decrease in the ability of the pulmonary artery to vasoconstrict at birth may prove to be a protective mechanism.

In this study, we have demonstrated maturational changes in the contractile responsiveness of the pulmonary artery vascular smooth muscle to norepinephrine and developmental changes in the modulation of contractility by endothelial $\alpha_{2}$-adrenoceptors. The relative unresponsiveness of newborn intrapulmonary arteries to muscarinic (8) and $\alpha_{2}$-mediated EDRF release may mean that these mechanisms have a limited role in the adaptation of the pulmonary circulation to extrauterine life.

\section{REFERENCES}

1. Palmer RMJ, Ferrige AG, Moncada S 1987 Nitric oxide release accounts for the biological activity of endothelium derived relaxing factor. Nature 327:524-526

2. Ignarro LJ, Buga GM. Wood KS, Byrnes RE, Chaudhuri G 1987 Endothelium derived relaxing factor produced and released from artery and vein is nitric oxide. Proc Natl Acad Sci USA 84:9265-9269

3. Ignarro LJ, Byrnes RE, Buga GM, Wood KS 1987 Endothelium derived relaxing factor from pulmonary artery and vein possesses pharmacological and chemical properties identical to those of nitric oxide radical. Circ Res 61:866-879

4. Teitel DF, Iwamoto IIS, Rudolph AM 1990 Changes in pulmonary circulation during birth related events. Pediatr Res 27:372-378

5. Su C, Bevan JA, Assali NS, Brinkmam CR 1977 Regional variation of lamb blood vessel responsiveness to vasoactive agents during fetal development. Circ Res 41:844-848

6. Zubrow AB. Imaizumi SO. Tulenko TN 1989 Endothelium-mediated relaxation in the fetal pulmonary artery. Pediatr Res 25:75A(abstr)

7. Zellers TM, Vanhoutte PM 1991 Endothelium-dependent relaxation of piglet pulmonary arteries augment with maturation. Pediatr Res 30:176-180

8. Liu S, Hislop AA, Haworth SG, Barnes PG 1992 Developmental changes in the endothelium-dependent pulmonary vasculature. $\mathrm{Br} \mathrm{J}$ Pharmacol 106:324-330

9. Haworth SG, Hislop AA 198 I Adaptation of pulmonary circulation to extrauterine life in pig and its relevance to the human infant. Cardiovase Res 15:108-119

10. Hall SM, Haworth SG 1986 Normal adaptation of pulmonary arterial intima to extrauterine life in the pig: ultrastructural studies. J Pathol 149:55-66

11. Hall SM, Haworth SG 1987 Conducting pulmonary arteries: structural adaptation to extrauterine life in the pig. Cardiovase Res 21:208-216

12. Davidson D 1988 Pulmonary haemodynamics at birth: effect of acute cyclooxygenase inhibitors in lambs. J Appl Physiol 64:1676-1682

13. Davidson D 1987 Circulating vasoactive substances and haemodynamic adjustments at birth in lambs. J Appl Physiol 63:676-684

14. Fineman JR. Chang R. Soifer SJ 19911 -Arginine a precursor of EDRF in vitro, produces pulmonary vasodilation in lambs. Am J Physiol 261:H1563H1569

15. Wilson L. Stuart-Smith K. Haworth SG 1992 Endothelial-dependent relaxations to norepinephrine in porcine pulmonary arteries are mediated by alpha2 adrenoceptors. Am Rev Respir Dis 145:A 162(abstr)

16. Rees DD. Palmer RMJ. Hodson HF, Moncada S 1986 A specific inhibitor of nitric oxide formation from 1-arginine attenuates endothelium dependent relaxation. Br J Pharmacol 198:418-424

17. Davidson D. Eldermerdash $A 1991$ Endothelium-derived relaxing factor: evidence that it regulates pulmonary vascular resistance in isolated guinea-pig lung. Pediatr Res 29:538-542

18. Fineman JR, Heymann MA Soifer SJ 1991 N-w-nitro-L-arginine attenuates endothelium-dependent pulmonary vasodilation in lambs. Am J Physiol 260:111299-111306

19. Cocks TM, Angus JA 1983 Endothelium dependent relaxation of coronar arteries by noradrenaline and serotonin. Nature 305:627-630

20. Miller VM. Vanhoutte PM 1985 Endothelial alpha 2-adrenoceptors in canine pulmonary and systemic blood vessels. Eur J Pharmacol 118:123-129

21. Wharton J. Haworth SG, Polak J 1988 Postnatal development of the innervation and paraganglia in the porcine pulmonary artery bed. J Pathol 154 $19-27$

22. Abman SH, Chatfield BA. Rodman DM, Hall SL. McMurtry IF 1991 Maturational changes in endothelium-derived relaxing factor activity of ovine pulmonary arteries in vitro. Am J Physiol 260:L280-L285

23. Dunn JA. Lorch V, Sinha SN 1989 Responses of small intrapulmonary arteries to vasoactive compounds in the fetal and neonatal lamb: norepinephrine. epinephrine, serotonin and potassium chloride. Pediatr Res 25:360-36.3

24. Buckley NM. Gootman PM. Yellin EL. Brazeau P 1979 Age-related cardiovascular effects of catecholamines in anaesthetized piglets. Circ Res 45 : 282-292 